\title{
Estimate the lifetime of thermoluminescence traps in general-orders of kinetics model of chilli powder samples by using the $\mathrm{R}$ package TGCD
}

- Nguyen Duy Sang

Can Tho University, Can Tho

Faculty of Physics and Engineering Physics, University of Science, VNU-HCM

- Tran Van Hung

- Nguyen Quoc Hien

Research and Development Center for Radiation Technology, VAEI, Ho Chi Minh

- Nguyen Van Hung

Nuclear Research Institute, VAEI, Dalat

(Received on $20^{\text {th }}$ December 2016, accepted on $30^{\text {th }}$ October 2017)

\section{ABSTRACT}

The kinetic parameters of thermoluminescene (TL) glow peaks of chilli powder irradiated by gamma rays with the different doses of 0,4 and 8 $k G y$ (i.e. activation energies $(E)$, order of kinetics (b), trapping and recombination probability coefficients $(R)$ and frequency factors (s)) have been determined and evaluated by glow curve deconvolution (GCD) method using the glow curve data to estimate lifetime of TL traps. The kinetic parameters of $T L$ glow peaks are Key words: Lifetime, thermoluminescence, kinetic parameters, GCD, GOK, chilli

\section{INTRODUCTION}

Thermoluminescene (TL) technique is based on the luminescence emission from polymineral phases (mainly quartz, carbonates, feldspars and clays) isolated from foodstuffs [1]. The TL is empirically observed by heating a previously irradiated dosimeter. The TL intensity emitted as a function of temperature is called a glow curve. The emission glow peaks characteristics of a glow curve depend on trapping centres at different trap depths. The initial irradiation stores TL energy in the crystal. The TL material usually calculated by modeled first-, second-, generalorders of kinetics (GOK) thanking to the computer by using the $R$ package TGCD. The results obtained as comparing the lifetime values of the three samples showed that the values of the $8 k G y$ irradiated-samples were the lowest whereas the $4 k G y$ irradiated-samples'value were greater than the non-irradiated samples' one time.

exhibits a very complex TL glow curve structure with non-well peaks so it cannot be analyzed by using the commonly accepted physical model to explain the trap structure [2]. The kinetic parameters of TL glow peaks are calculated by modeled first-, second-, general-orders of kinetics (GOK) thanking to the R package TGCD. There are various methods to explain TL process and to evaluate the kinetic parameters from TL glow curves. These analysing methods include: glow curve deconvolution (GCD), computerized glow curve deconvolution (CGCD), peak shape (PS), initial rise (IR), whole glow peak (WGP), 
isothermal decay (ID), three-points (TP), additive dose (AD) [3- 2- 4- 5] and etc. This paper reports on the estimation of the lifetime (GOK model) values calculated from the TL glow curves of chilli powder irradiated by gamma rays (stored $360 \mathrm{~h}$ or $720 \mathrm{~h}$ ) at different dose using GCD method by using the R package TGCD [6].

One of the problem of thermoluminescence dating is the estimation of the lifetime of the used peaks. The lifetime $(\tau)$ of each glow peak, which is an important factor for dating, is calculated from these three parameters: activation energies (E), frequency factors (s) and order of kinetics (b).

TL has numerous and varied applications, the most popular being in dosimetry and dating. In recent times it has also been shown to be extremely valuable in designing scintillators and persistent luminescent materials. One factor which is of paramount importance in any given application of TL is the lifetime of electrons in a trap. There are equations to evaluate lifetime in kinetic model but none in the differential order formalism. In this paper, an expression of $\tau$ for TL peaks in the GOK model has been derived.

\section{MATERIAL AND METHODS}

\section{Software description}

The R package TGCD is self-contained and does not depend on any other external $R$ package. Programs were developed using Fortran and were wrapped by $\mathrm{R}$ using an interface. The package was assessed using a variety of running platforms, and its latest version (version 1.9), including the User Manual, is downloadable from the Comprehensive R Archive Network (CRAN) (http://CRAN.Rproject.org/package=TGCD). The package can be downloaded and installed into $\mathrm{R}$ software by following the two subsequent steps: (i) download and install the package from CRAN via inputting the command install.packages("TGCD") into the $\mathrm{R}$ console; (ii) load the package using the command require(TGCD) [6].
To simulate a glow peak, the user needs to supply parameters, such as the initial concentration of trapped electrons, the frequency factor, the activation energy, the heating rate (hr), the trapping and recombination probability coefficients, the order of kinetics, etc. For GCD method, the user must supply temperature and TL signal values stored in a two-column data frame (or matrix). The data set can be loaded into the $\mathrm{R}$ console using the internal $\mathrm{R}$ function read.table(). Additional arguments that need to be specified for glow curve fitting include the number of glow peaks to be deconvoluted, the allowed maximum number of random trials, the allowed maximum total half-width of glow peaks, the allowed minimum distance between peak temperatures, etc. A plot showing deconvoluted glow peaks can be automatically produced once the calculation is terminated. The user can also specify a file to save the fit data for further usage [6].

\section{Materials}

The chilli powder was subdivided into about$20 \mathrm{~g}$ samples after collecting from the local supermarket in Vietnam, where the irradiation processing for food preservation has not yet implementated. The samples were irradiated inside polyethylene holders that had the same size and are suitable to be inserted inside the radiation facility. Before being irradiated and analyzed, the samples were stored in the dark at room temperature. TL analysis was also conducted on non-irradiated samples to check the reliability of the method in reality. This procedure recommended by the European Committee for Standardization [7] was followed to separate silicate minerals from the chilli powder samples. The resuspension in acetone was repeated to collect as much mineral as possible. The steel discs were previously cleaned with acetone and ultrasound treatment. The chilli powder samples as a whole, as well as minerals transferred on discs, were irradiated under

\section{Trang 72}


electronic equilibrium conditions with a Cobalt60 gamma irradiator (Gamma chamber GC-5000, BRIT, India) at the Nuclear Research Institute (NRI), Vietnam. The dose values were calculated to use irradiation time and the dose rate (3.6 $\mathrm{kGy} / \mathrm{h}$ ) measured with the Fricke dosimeter; the overall uncertainty in the absorbed dose of the irradiated chilli powder was less than $\pm 5 \%$. An Rexon-reader machine UL-320 (equipped with PC and Windows applications software) was used to record and analyze the TL curves; the instrumental settings were chosen as follow: initial temperature $\left(70{ }^{\circ} \mathrm{C}\right)$, speed heating: (5 ${ }^{\circ} \mathrm{C} / \mathrm{s}$ ), final temperature from $100{ }^{\circ} \mathrm{C}$ to $250{ }^{\circ} \mathrm{C}$. After mineral isolation and irradiation, specimens were stored at $50 \quad{ }^{\circ} \mathrm{C}$ overnight before TL measurements.

\section{Methods}

The lifetime $(\tau)$ of electron in a trap is vitally important on account of the utility of the TL peak associated with it. The limit of utility of the TL peak may be estimated on the basis of the magnitude of $\tau$. For instance, electrons with $10^{3}$ $\leq \tau \leq 10^{9}$ years are expected to be useful in dating. Thus it follows that the TL peaks of quartz and feldspar whose s meet these criterions are routinely employed in TL dating (see Appendix E, pp-272, Aitkin [8]). With regard to the suitability of TL for dosimetry, it is imperative that $\mathrm{s}$ be of the order of a few years. A TL peak in the range of $200-250{ }^{\circ} \mathrm{C}$ is expected to satisfy this criterion (see Table 1.1, pp-51 of [8] and Table 6.1, pp-218 of McKeever [1]). In addition to its value in TL dating and TL dosimetry recent research has proved that $\tau$ is of great importance in designing scintillators and persistent luminescence materials. $\tau$ in the first order kinetics is evaluated by the expression:

$$
\tau=\frac{\exp \left(\frac{E}{k T}\right)}{s}
$$

where, $\tau=$ lifetime (s); E = activation energy $(\mathrm{eV}) ; \mathrm{T}=$ storage temperature $(\mathrm{K}) ; \mathrm{k}=$
Boltzmann constant $(\mathrm{eV} / \mathrm{K}) ; \mathrm{s}=$ frequency factor $\left(\mathrm{s}^{-1}\right)$. Lovedy and Gartia [9] derived the expression of $\tau$ for general order kinetics

$$
\tau=\frac{\exp \left(\frac{E}{k T}\right)}{s(2-b)}
$$

where $b$ is the order of kinetics.

The subject of computerized curve fitting analysis has become very popular during the last two decades with the development of sophisticated GCD method [10]. The glow curves of TL materials are in most cases complex curves consisting of many overlapping glow peaks. Hence, the deconvolution of complex glow curves into their individual components is widely applied for dosimetric purposes and for evaluating the kinetic parameters using curve fitting methods [11]. GCD method is most advantage among the methods (i.e. IR, PS, ID, VHR etc.) due to simultaneous determination of kinetic parameters of all peaks without additional thermal treatments and experimental repetitions. In addition, GCD method is very important to decide correctly how many glow peaks there are in the complex glow curve and which of them have first-, second-, GOK [2]. The consistency of $\mathrm{E}, \mathrm{b}$ and $\mathrm{s}$ values evaluated from previously stated methods can be checked by the GCD method. Firstly, after determining the number and positions of peaks of the glow curve, the experimental glow curve is fitted with one or more of equations (3) to (5) [11].

The values of $\mathrm{E}, \mathrm{b}$ and $\mathrm{s}$ found from other methods are used as initial estimates in the process of making them fit. The computed curve is then compared with the actual experimental curve. Each of the parameters used is varied independently until a best fit is reached. The analytical equations for TL peaks using this method are derived from the basic kinetic TL equations. The equations considers two measured experimental quantities, the maximum intensity $\mathrm{I}_{\mathrm{M}}$ and the maximum temperature $\mathrm{T}_{\mathrm{M}}$, as follows: 
(i) For first order kinetics

$I(T)=I_{M} \exp \left[1+\frac{E}{k T} \frac{T-T_{M}}{T_{M}}-\frac{T^{2}}{T_{M}{ }^{2}} \times\right.$
$\left.\exp \left(\frac{E}{k T} \frac{T-T_{M}}{T_{M}}\right)\left(1-\frac{2 k T}{E}\right)-\frac{2 k T_{M}}{E}\right]$

(ii) The form of the second order kinetics

$I(T)=$

$4 I_{M} \exp \left(\frac{E}{k T} \frac{T-T_{M}}{T_{M}}\right)\left[\frac{T^{2}}{T_{M}{ }^{2}} \exp \left(\frac{E}{k T} \frac{T-T_{M}}{T_{M}}\right)(1-\right.$

$\left.\left.\frac{2 k T}{E}\right)+1+\frac{2 k T_{M}}{E}\right]^{-2}$

(iii) Analytical equation for general order kinetics

$I(T)=I_{M} b^{\frac{b}{b-1}} \exp \left(\frac{E}{k T} \frac{T-T_{M}}{T_{M}}\right)[(b-$

1) $\frac{T^{2}}{T_{M}^{2}} \exp \left(\frac{E}{k T} \frac{T-T_{M}}{T_{M}}\right)\left(1-\frac{2 k T}{E}\right)+1+$

$\left.(b-1) \frac{2 k T_{M}}{E}\right]^{-\frac{b}{b-1}}$

The accuracy of these analytical TL equations is numerically expressed by calculating

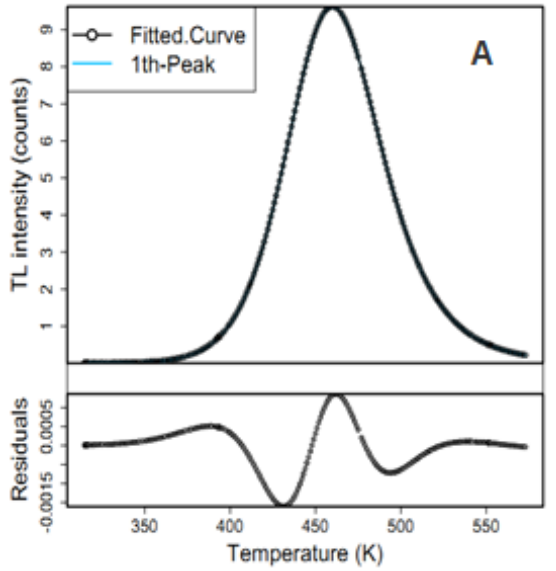

the figure of merit (FOM) [12]. The FOM is given by

$$
F O M=\frac{\sum_{p}\left|y_{\text {exp }}-y_{f i t}\right|}{\sum_{p} y_{f i t}}
$$

where $y_{\exp }$ and $y_{\text {fit }}$ are the experimental data and the values of the fitting function, respectively.

\section{RESULTS AND DISCUSSIONS}

The TL glow curves of chilli powder stored $360 \mathrm{~h}$ and $720 \mathrm{~h}$ recorded for $0,4,8 \mathrm{kGy}$ gamma radiation dose were given in Fig. 1, Fig. 2, Fig. 3. It has been found that the TL intensity of the 8 $\mathrm{kGy}$ is much stronger than that of the $4 \mathrm{kGy}$ and non-irradiated samples. The $\mathrm{E}, \mathrm{b}$ and $\mathrm{s}$ values are calculated based on fitting the glow curve. The analyzed TL glow curves consist of the single glow peaks.

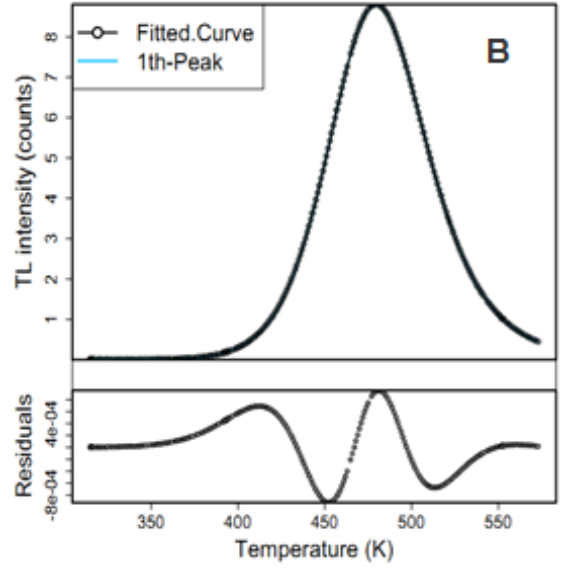

Fig. 1. Fitting TL glow curve of non-irradiated chilli powder samples stored $360 \mathrm{~h}$ (A) and $720 \mathrm{~h}$ (B)
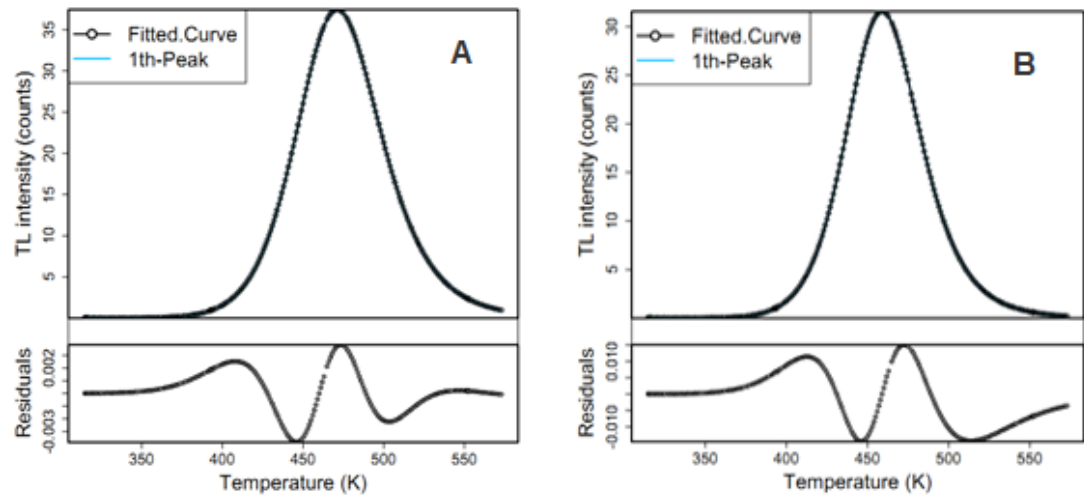

Fig. 2. Fitting TL glow curve of chilli powder samples irradiated with 4 kGy stored $360 \mathrm{~h}$ (A) and $720 \mathrm{~h}$ (B)

\section{Trang 74}



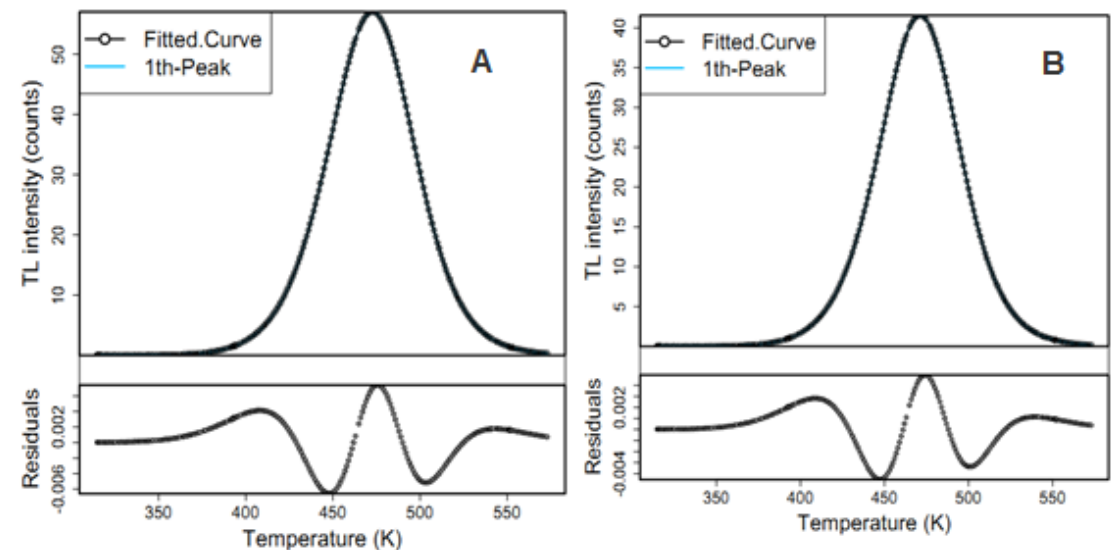

Fig. 3. Fitting TL glow curve of chilli powder samples irradiated with 8 kGy stored $360 \mathrm{~h}$ (A) and $720 \mathrm{~h}$ (B)

The intensity of the $8 \mathrm{kGy}$ irradiated aliquots decreases with the elapsed time due to the fading effect that also contributes to modify the shape of the curve.

The results are given Table 1 . Such behaviour is well correlated with the estimated $\mathrm{E}$ value for non-irradiated sample stored from $360 \mathrm{~h}$ to $720 \mathrm{~h}$, this kinetic parameter is gradually increasing with the elapsed time from 0.89705 to $0.996022 \mathrm{eV}$ (non-irradiated sample); 1.00713 to $1.10783 \mathrm{eV}$ (4 kGy-irradiated sample) and
0.95771 to $0.99276 \mathrm{eV}$ (8 kGy-irradiated sample). Therefore, we can consider that the estimation of the E values using the GCD method could be used to determine the length of time between irradiation processing and the TL analysis. Such values of trap depth parameters indicate the lifetime of electron in these traps. Approximately, the $\mathrm{E}$ value of the TL chilli powder sample irradiated with $4 \mathrm{kGy}$ was determined to have a greater value than the others [13].

Table 1. Fitting TL glow curves of the chilli powder irradiated with 0,4 and $8 \mathrm{kGy}$ (stored $360 \mathrm{~h}$ and $720 \mathrm{~h}$, storage temperature $\approx 300 \mathrm{~K}$ )

\begin{tabular}{|c|c|c|c|}
\hline Dose & Peaks & $360 \mathrm{~h}$ & $720 \mathrm{~h}$ \\
\hline \multirow{5}{*}{$0 \mathrm{kGy}$} & $\mathrm{E}(\mathrm{eV})$ & 0.89705 & 0.96022 \\
\hline & $\mathrm{s}\left(\mathrm{s}^{-1}\right)$ & $1.56 \times 10^{9}$ & $2.80 \times 10^{9}$ \\
\hline & $\mathrm{b}$ & 1.98916 & 1.99001 \\
\hline & FOM & 0.017 & 0.016 \\
\hline & $\tau(\mathrm{h})$ & 19315 & 134457 \\
\hline \multirow{5}{*}{4 kGy } & $\mathrm{E}(\mathrm{eV})$ & 1.00713 & 1.10783 \\
\hline & $\mathrm{s}\left(\mathrm{s}^{-1}\right)$ & $0.15 \times 10^{11}$ & $4.22 \times 10^{11}$ \\
\hline & $\mathrm{b}$ & 1.99143 & 1.99335 \\
\hline & FOM & 0.015 & 0.013 \\
\hline & $\tau(\mathrm{h})$ & 179605 & 404583 \\
\hline \multirow{5}{*}{8 kGy } & $\mathrm{E}(\mathrm{eV})$ & 0.95771 & 0.99276 \\
\hline & $\mathrm{s}\left(\mathrm{s}^{-1}\right)$ & $0.39 \times 10^{10}$ & $1.04 \times 10^{10}$ \\
\hline & $\mathrm{b}$ & 1.59347 & 1.61000 \\
\hline & FOM & 0.022 & 0.020 \\
\hline & $\tau(\mathrm{h})$ & 2153 & 3264 \\
\hline
\end{tabular}


The values of $\mathrm{s}$ of chilli powder samples irradiated with 0,4 and $8 \mathrm{kGy}$ according to GCD method of the three TL glow peak were also determined as $1.56 \times 10^{9}, 0.15 \times 10^{11}, 0.39 \times 10^{10}$ (stored $360 \mathrm{~h}$ ) and $2.8 \times 10^{9}, 4.22 \times 10^{11}, 1.04 \times$ $10^{10}$ (stored $720 \mathrm{~h}$ ). It can be said that the increase or the decrease of $\mathrm{s}$ is due to fewer or greater number of release of the trapped electrons per unit time. Frequency factor is a measure of the likelihood of escape per unit of time with the help of heat energy of the electrons in traps. The order of kinetic of chilli powder samples irradiated with 0,4 and $8 \mathrm{kGy}$ were determined as $1.98916,1.99143,1.59347$ (stored $360 \mathrm{~h}$ ) and $1.99001,1.99355,1.61000$ (stored 720 h). The values of lifetime of chilli powder samples irradiated with 0,4 and $8 \mathrm{kGy}$ were determined as $19315,179605,2153 \mathrm{~h}$ (stored $360 \mathrm{~h}$ ) and 134457, 404583, $3264 \mathrm{~h}$ (stored $720 \mathrm{~h}$ ).

Glow-curves with FOM values in excess of 5 $\%$ are subjected to further investigation to determine the reasons for the poor fit. From many experiences, it can be said that, if the values of the FOM are between $0.0 \%$ and $2.5 \%$, the fit is good, $2.5 \%$ and $3.5 \%$ is small flow, and $>3.5 \%$ is bad [2].

The results obtained as comparing the kinetic parameters values of the three samples showed that the value of non-irradiated samples was lowest whereas the $4 \mathrm{kGy}$ irradiated-samples' value was greater than the $8 \mathrm{kGy}$ irradiatedsamples' one time. Compared to the detection of irradiation food based on the normal the glow curve [7-14-16], this method was calculated to ensure the fewest errors. It can be said that the differences between the results are connected to the limitations of the methods applied. It has been also determined in the literature that the kinetic parameters reported by different authors are not consistent. Leaving aside the experimental errors, even if one uses the same data for obtaining the trap depth, the values of the kinetic parameters obtained by various methods can differ appreciably. As E enters in the exponent of the expression of $\mathrm{s}$, a small variation in $\mathrm{E}$ leads to a large change in the calculated value of $s$ [2].

\section{CONCLUSIONS}

Kinetic parameters of TL chilli powder samples irradiated with 0,4 and $8 \mathrm{kGy}$ were calculated by the GCD method using the R package TGCD. The samples spending the shorter period of storage time have the smaller E, $\mathrm{b}, \mathrm{s}$ and $\tau$ values than the samples spending the longer period of storage time. Therefore, we can consider that the estimation of the $\mathrm{E}, \mathrm{b}, \mathrm{s}$ and $\tau$ values using the GCD method could be used to determine the length of time between irradiation processing and the TL analysis. The results obtained by comparing three-samples' lifetime values, the $8 \mathrm{kGy}$ irradiated samples get the lowest values while the $4 \mathrm{kGy}$ irradiated samples' values were greater than the non-irradiated samples' ones. The results obtained by different models indicated that the kinetic parameters of all glow peaks highly dependent on the shape of the glow curve.

Acknowledgements: This research was supported by the Nuclear Research Institute (NRI) of Vietnam in 2015

\section{Trang 76}




\section{Ước lượng thời gian sống của bẫy nhiệt phát quang trong mô hình bậc động học tổng quát của mẫu bột ớt sử dụng gói TGCD của phần mềm $\mathrm{R}$}

- Nguyễn Duy Sang

Trường Đại học Cần Thơ

Trường Đại học Khoa học Tự nhiên, ĐHQG-HCM

- Trần Văn Hùng

- Nguyễn Quốc Hiến

Trung tâm Nghiên cứu và Triển khai Công nghệ Bức xạ TP. HCM

- Nguyễn Văn Hùng

Viện Nghiên cứu Hạt nhân Đà Lạt

\section{TÓM TẮT}

Thông số động học nhiệt phát quang (TL) của mẫu bột ót được chiếu xa với các liều chiếu khác nhau 0; 4 và 8 kGy (độ sâu bẫy (E), bậc động học (b), hệ số tái hợp $R$ và hệ số tần số (s)) được xác định và ước lượng bằng cách làm khớp sử dụng dũ liệu tù đường cong để tính thời gian sống TL của bẫy. Các thông số động học được tính theo mô hinh bậc 1, bậc 2 hoặc bậc tổng quát dụa vào máy tính nhò̀ gói $T G C D$ của phần mềm R. Kết quả thu được khi so sánh giá trị thòi gian sống của ba mẫu, thấy rằng mẫu chiếu xa 8 kGy có giá trị thấp nhất, trong khi mẫu chiếu xạ 4 kGy lớn hơn mẫu không chiếu xạ.

Tù khóa: Thời gian sống, nhiệt phát quang, thông số động học, GCD, GOK, ót bột

\section{TÀI LIỆU THAM KHẢO}

[1]. S.W.S. McKeever, Thermoluminescence of solids, Cambridge University Press: London (1985).

[2]. N. Kucuk, A.H. Gozel, M. Yuksel, T. Dogan, M. Topaksu, Thermoluminescence kinetic parameters of different amount Ladoped $\mathrm{ZnB}_{2} \mathrm{O}_{4}$, Appl. Radiat. Isot., 104, 186 (2015).

[3]. M. Isik, T. Yildirim, N.M. Gasanly, Determination of trapping parameters of thermoluminescent glow peaks of semiconducting $\mathrm{Tl}_{2} \mathrm{Ga}_{2} \mathrm{~S}_{3} \mathrm{Se}$ crystals, $J$. Physics Chem. of Solids, 82, 56-59 (2015).

[4]. M.H.A. Mhareb, S. Hashim, S.K. Ghoshal, Y.S.M. Alajerami, M.A. Saleh, S.A.B. Azizan, N.A.B. Razak, M.K.B. Abdul
Karim, Influences of dysprosium and phosphorous oxides co-doping on thermoluminescence features and kinetic parameters of lithium magnesium borate glass, J. Radioanal Nucl. Chem., 305, 469 (2015).

[5]. A.M. Sadek, H.M. Eissa, A.M. Basha, G. Kitis, Resolving the limitation of the peak fitting and peak shape methods in the determination of the activation energy of thermoluminescence glow peaks, J. Lumin, 146, 418 (2014).

[6]. J. Peng, J. More, B. Garbow, K. Hillstrom, J. Burkardt, L.R. Petzold, A.C. Hindmarsh, R.W. Setzer, Thermoluminescence Glow Curve Deconvolution, University of 
Chinese Academy of Sciences, Beijing, China (2016).

[7]. E. 1788, Foodstuffs-Thermoluminescence detection of irradiated food from which silicate minerals can be isolated, Brussels: European Committee of Standardization (2001).

[8]. M.J. Aitkin, Thermoluminescence Dating, Academic Press, New York (1985).

[9]. L. Lovedy, R.K. Gartia, Derivation of an expression for lifetime $(\tau)$ in OTOR model, J. Nucl. Instrum. Methods B, 21-23 (2013).

[10]. Y.S. Horowitz, D. Yossian, Computerised glow curve deconvolution: application to thermoluminescence dosimetry, Radiat. Prot. Dosim, 60, 293- 295 (1995).

[11]. V. Pagonis, G. Kitis, C. Furetta, Numerical and Practical Exercises in Thermoluminescence, Springer, United States of America (2006).

[12]. G. Kitis, TL glow-curve deconvolution functions for various kinetic orders and continuous trap distribution: Acceptance criteria for E and s values, J. Radioanal. Nucl. Chem., 247, 697-703 (2001).
[13]. V. Correcher, J. Garcia-Guinea, Potential use of the activation energy value calculated from the thermoluminescence glow curves to detect irradiated food, J. Radioanal. Nucl. Chem., 298, 821-825 (2013).

[14]. S. Elahi, I. Straub, K. Thurlow, P. Farnell, M. Walker, Referee analysis of suspected irradiated food, Food Control, 19, 269 (2008).

[15]. B. Engin, Thermoluminescence parameters and kinetics of irradiated inorganic dust collected from black peppers, Food Control, 18, 243 (2007).

[16]. N.D. Sang, N. Van Hung, T. Van Hung, N.Q. Hien, Using the computerized glow curve deconvolution method and the $\mathrm{R}$ package TGCD to determine of thermoluminescence kinetic parameters of chilli powder samples by GOK model and OTOR one, Nuclear Instruments and Methods in Physics Research Section B: Beam Interactions with Materials and Atoms, 394, 113-120 (2017).

\section{Trang 78}

